\title{
Infiltrating Bladder Carcinoma
}

National Cancer Institute

\section{Source}

National Cancer Institute. Infiltrating Bladder Carcinoma. NCI Thesaurus. Code C150570.

A carcinoma that arises from the bladder mucosa and invades the bladder wall. 